Est Ag 53 (2018) 383-412

\title{
La génesis del rito bautismal cristiano
}

\author{
D. Álvarez Cineira
}

RESUMEN: La dificultad de rastrear los orígenes del rito iniciático cristiano del bautismo ha llevado a buscar ciertas analogías en las religiones mistéricas del mundo greco-romano y, especialmente, en el mundo judío (los ritos de purificación del mar Muerto o en el baño de inmersión de los gentiles). Sin embargo, será la praxis bautismal de Juan la que se convierta en modelo inspirador del bautismo cristiano tras la Pascua, el cual llegará a ser el rito iniciático por excelencia de las primitivas comunidades cristianas para la incorporación de nuevos miembros. Para su adopción pospacual influyó de forma relevante el bautismo de Jesús a manos de Juan, para otorgarle un nuevo significado al realizarse en el "nombre de Jesús".

PAlABRAS ClAVE: Bautismo; Juan el bautista, Bautismo de Jesús, religiones mistéricas, prosélitos, Qumrán.

SUMARY: The difficulty of tracing the origins of the Christian initiatory rite of baptism has led to the search of certain analogies in the mystery religions of the Greco-Roman world and, especially, in the Jewish world (the rites of purification of the Dead Sea or in the immersion bath of the gentiles). However, it will be the baptismal praxis of John the Baptist that will become the inspiring model of Christian baptism after Easter, which became the initiatory rite par excellence of the early Christian communities for the incorporation of new members. The baptism of Jesus at the hands of John played a great influence on their Christian adoption and gave to it a new meaning by performing it in the "name of Jesus".

KEYWORDs: Baptism; John the Baptist, Baptism of Jesus, mystery religions, proselytes, Qumran. 
En base a dos textos bíblicos, Mt 28,16-20 y Mc 16,14-16, parecería que los orígenes del rito de iniciación cristiana son claros y evidentes. Lo que las iglesias realizan actualmente en sus ritos iniciáticos, tendría su origen en la disposición explícita del Jesús resucitado, quien exhortó a sus seguidores a promover un proceso de evangelización para hacer discípulos, prescribiéndoles enseñar y bautizar.

Los estudios modernos de NT, sin embargo, invitan a ser cautos en este punto. Así, forma parte del acervo exegético el hecho de que Mc 16,14-16 no pertenecía al texto original del evangelio, ya que este concluía en Mc 16,8; en un momento posterior, sin embargo, se añadieron tres apariciones del resucitado y el mandato misionero con el objeto de armonizarlo con los relatos post-pascuales de otros evangelios ${ }^{1}$. Igualmente se han planteado serias dudas acerca de la fiabilidad de los detalles de Mt 28,16-20. En concreto, es difícil conciliar la frase formularia "en el nombre del Padre, y del Hijo y del Espíritu Santo" y el enfoque misionero orientado a "todas las naciones" con

1 Para las cuatro variantes conclusivas del Ev. de Mc, cf. Bruce M. Metzger, A Textual Commentary on the Greek New Testament, United Bible Society, London - New York 1971, 122-128. En contra de su originalidad: Craig A. EvAns, Mark 8:27-16:20 (WBC 34b), Thomas Nelson Publishers, Nashville 2001, 545ss.; Adela Yarbro Collins, Mark. A Commentary (Hermeneia), Forstress, Minneapolis, MN 2007, 802-807; Joel MARcus, El Evangelio según Marcos (Mc 8-16) (=BEB 131), Sígueme, Salamanca 2011, 1257-1267. Eta Linnemann, "Der (wiedergefundene) Markusschluss", en ZThK 66 (1969) 255-287, opina que Mc 16,15-20 es original del evangelista, mientras que los vv. 9-14 no. En contra se expresa Kurt Aland, "Der wiedergefundene Markusschluß? Eine methodologische Bemerkung zur textkritischen Arbeit", en ZThK 67 (1970) 3-13, quien considera la versión breve como original. Jeanine DePASSELivet, Le Problème de la finale de Marc. Mc 16:8, Etat de la Question, 9-36, tesis presentada en Lovaina en 1970, ofrece un resumen del debate sobre la autenticidad de Mc 16,9-20. Walter Schmiтhals, "Der Markusschluß, die Verklärungsgeschichte und die Aussendung der Zwölf", en ZThK 69 (1972) 379-411, considera que Mc 16,15-20 pertenecía originalmente a un final de una fuente que fue empleada por el evangelista, por tanto, previa a Mc. Por su parte, William R. FARMER, The Last Twelve Verses of Mark (=SNTS MS 25), Cambridge University Press, Cambridge 1974, 109, deja la cuestión abierta, tanto a partir de los testimonios externos como de las evidencias internas, aunque personalmente se inclina por su autenticidad. Cfr. otros estudios: Camille FocANT, "La canonicite de la finale longue (Mc 16,9-20): vers la reconnaissance d'un double texte canonique?", en J.-M. Auwers - H.J. De Jonge (eds.), The Biblical Canons, Leuven University Press, Leuven 2003, 587-597; Gregor EMMENEGGER, "Ein koptisches Amulett als Beleg für den kurzen Markusschluss", en ZNW 103 (2012) 142-145; Stuart G. HALl, "How did Mark end? An alternative", en Theol 105 (2002) 45-48; Norman R. Petersen, "When is the End not the End? Literary Reflections on the Ending of Mark's Narrative", en Interp 34 (1980) 151-166; John Christopher Thomas, "A Reconsideration of the Ending of Mark", en JETS 26 (1983) 407-419. 
el Jesús histórico. Este tipo de lenguaje trinitario y el cambio de énfasis de una misión predominantemente judía por parte de Jesús a una misión casi exclusivamente dirigida a los gentiles, parecen reflejar el desarrollo posterior de la vida de la iglesia primitiva. Por consiguiente, este pasaje representaría la práctica catequética y litúrgica propia de la comunidad de Mateo a finales de los años 80 puesta en boca de Jesús y la forma en que esa comunidad entendía sus responsabilidades misionales ${ }^{2}$.

Si la fiabilidad histórica de estos dos textos, que atribuyen la iniciación cristiana a un mandato explícito de Jesús, es cuestionable, entonces ¿qué podemos saber con cierto grado de certeza acerca de los orígenes de este rito a partir de los textos neotestamentarios? En los primeros escritos cristianos, que fueron compilados posteriormente en lo que se convirtió el Nuevo Testamento, se menciona el bautismo con gran naturalidad, dándolo por supuesto, y testimonian ampliamente la existencia de dicho rito en las comunidades cristianas. Sin embargo, esos textos no ofrecen respuesta a la cuestión planteada. Tampoco existió un solo modelo ritual para la iniciación cristiana que pudiera ser considerado como universalmente "normativo". Al contrario, desde sus orígenes, la práctica litúrgica cristiana de la iniciación refleja una considerable variedad y multiplicidad de formas ${ }^{3}$, tanto en sus modelos rituales, como en sus diferentes interpretaciones teológicas. Ya que los evangelios ofrecen diversas referencias al bautismo de Jesús a manos de Juan el Bautista, entonces se debe prestar atención a los orígenes del bautismo de Juan y al significado del bautismo de Jesús para investigar la génesis, la práctica y la interpretación teológica del rito de iniciación cristiana, aunque aquí abordaremos solo su origen.

\section{Antecedentes del baUtismo Cristiano}

El uso de agua y el baño como medios de purificación estaban ampliamente extendidos en las antiguas culturas y religiones de Oriente y del

2 Ulrich Luz, El Evangelio según San Mateo. Mt 26-28 (Vol. IV) (=BEB 115), Sígueme, Salamanca 2005,552ss: "el mandato bautismal podría tener su origen, por una u otra vía, en la liturgia de la comunidad mateana" (p. 553). Según W.D. DAvies - Dale C. Allison Jr, The Gospel according to Saint Matthew. Vol. III (=ICC), T \& T Clark, Edinburgh 1997, $683-$ 688 , el texto proporciona una etiología para el bautismo cristiano.

3 Cf. D. Álvarez CineIRA, "El bautismo de Felipe, ¿un bautismo deficitario? (Hch 8,5-24), en EstAg 52 (2017) 207-240. 
Mediterráneo ${ }^{4}$. En los lugares sagrados solían existir fuentes y otras provisiones de agua para ser usadas en los ceremoniales de purificación de los adoradores y oficiantes en el santuario. Purificaciones preliminares realizadas mediante abluciones, lavados o inmersiones formaban parte de ceremonias y eran elementos esenciales de muchas religiones del mundo egipcio, greco-romano, así como de las religiones mágicas y mistéricas. Así pues, los historiadores de las religiones buscaron modelos y paralelismos en esos contextos cultuales que pudieran explicar la génesis del bautismo cristiano. No obstante, los elementos más cercanos se encuentran en el mundo religioso judío y, especialmente, en Juan el Bautista, como veremos a continuación.

\section{El mundo greco-romano}

El eminente egiptólogo Alan Gardiner propuso la estrecha analogía entre el bautismo cristiano y el denominado "bautismo del faraón" o "lustración de coronación". Se trataba de un acto simbólico en el que dos deidades vertían agua sobre el rey para su purificación, rito que tenía lugar tras la salida del rey de su palacio y antes de la coronación por parte de los dioses. En el esquema tripartito de un "rito de paso", la purificación adquiría el significado de la conversión o transformación. La primera fase de los ritos de separación, mediante los cuales el iniciando es segregado de la comunidad durante un tiempo, estaba marcada por el abandono del palacio, mientras que la tercera etapa, tras la fase liminal, acontecía en la coronación del monarca, por lo que se reintegraba en su reino con un status novedoso. Esta coronación, repetida ritualmente, se interpretó como un rejuvenecimiento o incluso como el renacimiento del monarca. La propuesta de Alan Gardiner, sin embargo, no encontró aceptación entre los eruditos 5 .

4 Johannes LEIPOLDT, Die urchristliche Taufe im Lichte der Religionsgeschichte, Dörflling \& Franke, Leipzig 1928, 38-56 incluye sumarios de ritos iniciáticos de las principales religiones mistéricas. Véasen también Arthur Darby Nock, "Early Gentile Christianity and Its Hellenistic Background", en A.E.J. RAwLINSON (ed.), Essays on the Trinity and the Incarnation, Longmans, Green \& Co., London 1928, 111-120, reimpreso en Zeph Stewart (ed.), Arthur Darby Nock: Essays on religion and the Ancient World, Oxford

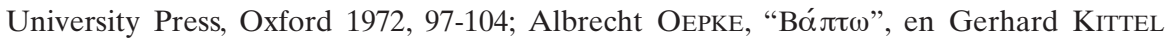
(ed.), Theological Dictionary of the New Testament Vol. I, Eerdmans, Grand Rapids 1964, 530-535; Joseph Ysebaert, Greek Baptismal Terminology. Its Origins and early Development, Dekker \& van de Vegt, Nijmegen 1962,12-20.

5 Jan AsSMANN - Andrea KUCHAREK, "Wasserriten im Alten Ägypten“, en David HeLlholm - Tor VegGe - Oyvind Norderval - Christer Hellholm (eds.), Ablution, Initiation and 
Mayor interés entre los representantes de la escuela de la Historia de las Religiones despertaron los ritos iniciáticos de las religiones mistéricas 6 en las que se celebraban ceremonias de purificación mediante el agua. En primer lugar, los estudiosos postularon una derivación genética de los sacramentos cristianos de los ritos cuasi-sacramentales de los cultos mistéricos (iniciación, abluciones, unciones, comidas sagradas); consideraron que los sacramentos cristianos no se basaban en el mensaje de Jesús, ni en el judaísmo bíblico de Palestina, sino más bien constituían el resultado de un proceso de helenización. En segundo lugar, adujeron que el mito de la muerte y resurrección de una divinidad, que se encuentra en el centro de cada culto, se aplicó a la muerte y resurrección de Jesús por influencia de estos cultos mistéricos.

La denominación de cultos mistéricos comprende un amplio grupo de cultos. Entre los más extendidos y conocidos en la antigüedad se encontraban los misterios de Eleusis, Dionisos, Atis, Isis y Mitras, amén de otros muchos. Aunque no es claro ni el origen ni el significado fundamental del concepto misterio, parece estar relacionado con "iniciar", "mantener cerrados los labios"..., en cuanto que se trata de una enseñanza secreta (disciplina arcani) destinada a un determinado grupo, que tenía que someterse a la iniciación en los misterios correspondientes. Las abluciones, sin embargo, no formaban parte de los ritos secretos y eran bien conocidas. Los ritos mistéricos variaban considerablemente en sus detalles, al igual que las condiciones de admisión y la forma en que se estructuraba la preparación.

Así, por ejemplo, en los misterios de Eleusis existían tres niveles de iniciación, aunque es posible que los antiguos griegos no separaran los dos primeros. El primer grado incluía una iniciación preliminar y tenía lugar antes o durante los Misterios Menores, celebrados durante el mes de Anthesterion (el mes de la primavera) a orillas del río Ilisos en Atenas. Sabemos muy poco acerca de los Misterios Menores. Su propósito pudo haber sido preparar a los participantes para los Misterios Mayores a través de una forma de iniciación preliminar, aunque parece que la participación en los Misterios Menores no era obligatoria. El con-

Baptism: Late Antiquity, Early Judaism and Early Christianity (=BZNW 176), W. de Gruyter, Berlin-Boston 2011, 43-68.

6 Walter Burkert, Cultos mistéricos antiguos, Trotta, Madrid 2005; Jaime Alvar, Los misterios. Religiones "orientales" en el imperio romano, Crítica, Barcelona 2001. 
tenido de la ceremonia consistía en sacrificios, baile y canto, ayuno y aspersiones de agua para la purificación, bajo la dirección de los mistagogos.

El segundo y tercer grado de iniciación tenían lugar durante los Misterios Mayores, que se celebraban una vez al año, a mediados del mes de Boedromion (septiembre), y su celebración se extendía durante nueve días ${ }^{7}$. Todo el mundo estaba autorizado a participar. El centro de las celebraciones era los hiera, los "objetos sagrados", que el día anterior al comienzo de la fiesta habían sido llevados en procesión desde Eleusis hasta el Ágora de Atenas y mantenidos en el Eleusinion, el santuario de Deméter. Al tercer día de la celebración, los candidatos se dirigían al mar entre Atenas y Eleusis para bañarse. Cada uno tomaba un cerdo para ser lavado con él y posteriormente el animal se sacrificaba a Demeter ${ }^{8}$. El baño en el mar y el sacrificio del cerdo eran purificaciones preliminares. La parte secreta de la ceremonia acontecía durante la noche del sexto al séptimo día, cuando tenía lugar el segundo grado de iniciación, el telete, abierto a los recién iniciados y a quienes habían sido iniciados en años anteriores. El grado más elevado de iniciación, la epopteia, se producía en el transcurso de la misma noche o a la noche siguiente, cuando los mystai se convertían en epoptai y tenía lugar el ritual de "la apertura de los ojos", por lo que podían contemplar la verdad. Es posible que los epoptai presenciaran un ritual que implicara el nacimiento de un niño (probablemente Pluto). Durante el octavo día, realizaban libaciones y ritos por los muertos.

La iniciación a los misterios de Dionisos incluía de igual modo un baño preliminar. La madre de Publio Aebutio afirma haber realizado un voto para iniciarle en los ritos de Baco y le explica que él tendrá que observar continencia durante 10 días. Al final de ese período, ella le conducirá a un banquete y después, tras un lavado ceremonial (pure lautum), al templo para la iniciación propiamente dicha ${ }^{9}$. Por su parte, Apuleyo, en su escrito Metamorfosis (asno de oro) ${ }^{10}$, escrito en el tercer cuarto del siglo II d.C., recoge el relato de la iniciación de Lucio en el culto de Isis

7 Walter BURKeRT, Greek Religión, Harvard University Press, Cambridge 1985, 285290, describe la secuencia de los eventos con referencia a las fuentes originales.

8 Plutarco, Foción 27,3 menciona a un iniciado lavando un lechoncito en el puerto de Pireo.

${ }^{9}$ Livio, Historia de Roma 39.9.4.

10 Apuleyo, Metamorfosis XI 23-24. 
en Corinto ${ }^{11}$. Los actos preliminares podían ser narrados abiertamente: "Cuando el sacerdote indicó el tiempo más propicio, rodeado por una multitud de devotos, fui conducido a los baños (balneas). Allí, tras haber realizado el baño habitual, Mitras (el sumo sacerdote del culto de Isis en Corinto) invocó el perdón de los dioses y, rociándome con agua, me limpió (abluit) de forma muy pura". Después trascurrían 10 días de ayuno. Sin traicionar los secretos del rito, Apuleyo indica detalles que los iniciados reconocían, pero que el resto de nosotros sólo podemos especular sobre su significado; se trata en realidad de la verdadera iniciación: "me aproximé a las fronteras de la muerte... En plena noche, vi el sol que brillaba en todo su esplendor. Me acerqué a los dioses del infierno y del cielo; los contemplé cara a cara y los adoré de cerca" (XI 23,7).

Cuando llegó la mañana, Lucio, ataviado con vestimentas de lino y portando una antorcha, fue presentado a la multitud. Él celebró este día festivo de iniciación como si fuera "mi feliz nacimiento a la vida religiosa" (XI 24,4). Las ceremonias iniciáticas concluían con una comida sacral celebrada tres días más tarde. Posteriormente, en Roma, Lucio recibió la iniciación en Osiris. En el relato, Apuleyo habla en dos ocasiones de sí mismo como renacido (renatus, XI 16) y del rito de dedicación como "realizado en la forma de una muerte voluntaria y de una vida obtenida por gracia” (XI 21).

En la actualidad, la investigación es escéptica sobre una posible influencia de los ritos de iniciación de los cultos mistéricos en el desarrollo y la concepción del bautismo cristiano. Quienes han visto similitudes en el uso del agua, han armonizado los baños preliminares con los efectos de la iniciación, interpretando de forma errónea los textos, o bien se apoyaban en escritores cristianos tardíos que cristianizaron el significado de las ceremonias mistéricas. Existe una diferencia significativa en el uso del agua. Las abluciones en el mundo politeísta constituían generalmente un rito preliminar para la iniciación; en el cristianismo, sin embargo, eran el centro de la iniciación para acceder a la comunidad ${ }^{12}$. Los ritos mistéricos lustrales no son cercanos a las comunidades cristianas primitivas y no

11 J. Gwyn Griffiths, Apuleius of Madauros, The Isis-Book (Metamorphoses, Book XI): Introduction, Translation and Commentary, Leiden, Brill 1975; María Cruz MaRín Ceballos, "La religión de Isis en las 'Metamorfosis' de Apuleyo", en HABIS 4 (1973) 127 179.

12 Günther Wagner, Pauline Baptism and the Pagan Mysteries, T \& T Clark, Edinburgh 1967. 
todos empleaban el agua como principal agente de la purificación ${ }^{13}$, aunque varios de sus rasgos pudieron ser adoptados y tamizados durante el proceso de la inculturación del cristianismo en su fase inicial. Por consiguiente, no se puede afirmar una derivación evolutiva del bautismo cristiano de rituales del mundo circundante, ni excluir toda conexión entre los dos mundos. No obstante, la génesis del bautismo cristiano hay que buscarla más bien en las abluciones rituales judías.

\section{El mundo judío}

El movimiento de seguidores de Jesús surgió dentro del judaísmo, así pues es de suponer que los conceptos y las prácticas judías proporcionaran un contexto inmediato más plausible para el bautismo cristiano que los vistos en el mundo greco-romano. La Ley de Moisés contenía todo un sistema de exigencias rituales en las que se empleaba el agua para abluciones o inmersiones con el objeto de lograr la purificación. Además suministraba imaginería (diluvio y el paso del Mar Rojo) y vocabulario, que los autores cristianos consideraron prefiguración del bautismo cristiano. No obstante, entre los judíos existió una considerable variedad de prácticas purificatorias rituales vinculadas a diferentes grupos, en las que el agua jugaba un papel relevante ${ }^{14}$. Esta variedad y, en ocasiones, falta de claridad de los textos dificulta establecer vínculos genéticos entre las prácticas judías y los orígenes del bautismo cristiano. Los escritos más elocuentes judíos al respecto proceden de épocas más tardías, como es el caso del sexto orden de la Misná, Purezas (toharot), que aborda las fuentes y lugares de impureza y los modos de purificación. Otros dos tratados de la misma obra están dedicados a este último tema: Pará/la vaca roja (cf. Num 19,1-10), y Miqwaot/baños rituales de inmersión (Lev 15,13) con el mandato de que la persona contaminada se lave en "aguas vivas".

13 Fritz GraF, "Baptism and Graeco-Roman Mystery Cults", en David Hellholm (eds.), Ablution 101-117.

14 Jonathan D. LAWRENCE, Washing in Water: Trajectories of Ritual Bathing in the Hebrew Bible and Second Temple Literature, Society of Biblical Literature, Atlanta 2006, analiza el lavado en la biblia hebrea, en la literatura del Segundo Templo, en los rollos del Mar Muerto y las evidencias arqueológicas para los baños rituales. Divide el uso de la terminología en tres categorías: ritual (general, sacerdotal, preparatorio para los neófitos), metafórico e iniciático. 


\section{a. La purificación en el judaísmo fuera de Qumrán}

La literatura del Segundo Templo proporciona indicios claros de prácticas de purificaciones rituales de los judíos piadosos, tanto en la patria como en la diáspora15. No sorprende pues, que uno de los testimonios escritos más antiguos de tal observancia provenga de la diáspora, donde la amenaza de preservar la identidad judía era mayor que en Palestina. No obstante, se encuentran pocas evidencias literarias acerca de las abluciones fuera de Qumrán y, generalmente, se refieren a reinterpretaciones de pasajes del AT. Tal es el caso del Testamento de Leví 9 (Ex 29,4; 40,12; Lev 1122; Ex 30,17-21), del Libro de los Jubileos 21,26 o de la Carta de Arísteas 305s. La falta de homogeneidad de los textos y la escasa utilización de la temática de la purificación en los escritos del judaísmo antiguo permiten reconocer a primera vista que los ritos de purificación no jugaron un papel relevante en sus contextos y los pasajes que los mencionan se integran en el horizonte de interpretación de la Escritura. No parece que existiera un rito establecido, ni conocemos el modo concreto de su realización.

A pesar de los escasos hallazgos, infiere Jonathan Lawrence una conclusión audaz referente a los posibles ámbitos de aplicación de los ritos de purificación en el judaísmo primitivo: "La misma diversidad de las prácticas descritas en estos textos sugiere que este período produjo una gran cantidad de innovaciones en la práctica del lavado ritual y su significado. No podemos decir de manera inequívoca cómo se llevaba a cabo la praxis concreta, pero podemos estar seguros de que estas prácticas se realizaban y se consideraron muy importantes" 16 . La mayor parte de los autores, por el contrario, se muestran mucho más cautos, pues no existen descripciones precisas sobre el modo de realización.

\section{b. Los ritos de purificación en los rollos del Mar Muerto}

La mayor parte de las evidencias del judaísmo antiguo referentes a los ritos de purificación se encuentran en los escritos del Mar Muerto. Entre ellos, a su vez, se pueden distinguir tres grupos de escritos: el Rollo del Templo (11Q19 / 11Q20), el material halájico procedente de Qumrán (4QpapRitPur = 4Q512; 4Q159; 4Q513; 4Q514; 4QMMT (4Q394-399), así

15 Josefo, Ant 3,262-265 y Filón, Spec Leg 1,262-262.

16 LAWrence, Jonathan D., Washing 78. 
como los escritos que regulan la vida de la comunidad, la denominada Regla de la comunidad de Qumrán, que contiene tres documentos referentes a lavados de purificación $(3,4-9 ; 4,21 ; 5,13 \mathrm{~s})$. Estos tres últimos textos, de mayor relevancia para nuestro tema que el resto de los otros dos grupos de escritos qumránicos, transmiten las reglas acerca de la admisión de nuevos miembros, así como indicaciones sobre las celebraciones anuales de la comunidad.

El complejo rito de iniciación (1QS 3,4-9) ${ }^{17}$ y la ceremonia de la renovación de la alianza funcionaron en Qumrán como un rito de paso estableciendo límites legales, sociales e ideológicos de la comunidad. La Regla de la Comunidad (1QS 5-6) describe el proceso por el que los aspirantes eran obligados a someterse a un elaborado proceso de instrucción y a pruebas diversas antes de ser admitidos en la Yahad (comunidad) ${ }^{18}$. Tras el escrutinio de los nuevos candidatos, se establecía la clasificación de su filiación y la jerarquía de los miembros de la comunidad, renovando la alianza con la comunidad de acuerdo con sus conocimientos y obras (1QS 1-2). La ceremonia constaba de seis elementos principales: a) la preparación, b) la aceptación de nuevos iniciados, c) bendiciones y maldiciones, d) la entrada en la serekh ${ }^{19}$, e) la purificación y la instrucción, f) la amonestación y la despedida ${ }^{20}$. El requisito principal para comenzar el proceso de

17 Este lavado será presentado como un acto único e irrepetible: "El que rechaza la alianza no será contado entre los perfectos; él ni se purificará por la expiación, ni se limpiará mediante las aguas purificadoras, ni se santificará por los mares y los ríos, ni será lavado por otras aguas. Impuro, será impuro. Durante el tiempo que desprecia los preceptos de Dios, no recibirá ninguna instrucción en la comunidad de su consejo" (1QS 3,4-6). Sigue una afirmación más positiva: "Porque es a través del espíritu de verdadero consejo acerca de los caminos del hombre que será expiado de todos sus pecados. Y cuando su carne sea salpicada por las aguas purificadoras y santificada por la limpieza del agua, será limpiada por la humilde sumisión de su alma a todos los preceptos de Dios" (1QS 3,7-9).

18 Josefo informa que, tras un período de prueba de un año en el que el aspirante observa de forma independiente el estilo de vida del grupo, se le permite participar de las aguas sagradas para sus purificaciones, pero todavía no es recibido en la vida comunitaria (Bell 2,138). La admisión definitiva del aspirante acontecía después de dos años de noviciado (Bell 2,122.139-142).

19 Para el contexto y trasfondo de la Regla de la Comunidad de Qumrán, cf. SCHOFIELD, Alison, From Qumran to the Yahad. A New Paradigm of Textual Development for the Community Rule, Brill, Leiden - Boston 2009, cap. 2-3.

20 Una descripción de este proceso se encuentra en ARNOLD, Russell C.D., The Social Role of Liturgy in the Religion of the Qumran Community (=Studies on the Texts of the Desert of Judah 60), Brill, Leiden - Boston 2006, 52-80. 
iniciación era el arrepentimiento, tras el cual se examinaba al iniciando en preparación para la ceremonia anual con el objeto de determinar su nivel de participación en la ceremonia y en la comunidad para el próximo año (1QS 6,13-23). Durante el primer año recibía instrucción acerca de las leyes de la comunidad, pero no tenía acceso a la "pureza de los Muchos". Después de participar en la ceremonia por segunda vez, tras un año de instrucción, se incorporaba al agua de la purificación y a la comida comunitaria. Sólo después de la finalización de su segundo año de formación venía aceptado como miembro de pleno derecho en la Yahad y podía ser incluido y clasificado en la serekh (regla) ${ }^{21}$.

La comunidad tenía una gran preocupación por las purificaciones y abluciones, aunque sus testimonios no son homogéneos, ni se describen sus procesos específicos ${ }^{22}$. La ablución formaba parte del rito de purificación, que constaba de otros elementos (ofrenda de sacrificios, oraciones...) y se repetían siempre que existiera impureza cultual. Parece ser que no existían unas formas ni ritos fijos estructurados. Más bien, los textos reflejan diferentes tipos de lavados, que se efectuaban en diferentes procesos dentro del judaísmo antiguo y/o en diferentes momentos de la vida comunitaria de la Yahad.

Una cuestión abierta en este campo es el objetivo del lavado. Por una parte, se lavan prendas de vestir, por otro lado hay personas que se bañan (¿desnudas o vestidas? $)^{23}$, o se lavan ciertas partes del cuerpo, como son las manos y los pies. No está claro cómo se realizaba la lustración o el baño en el agua, si ésta implicaba una inmersión total o parcial, o una aspersión con agua. Los textos tampoco determinan qué tipo de agua se

21 JOSEFO, Bell 2,119-158, distingue entre un rito inicial de purificación para los "novicios" y otro diario para los iniciados antes de participar en la comida común. Describe el acceso a las comidas comunitarias para el ya iniciado: "Después de haber hecho su tarea diligentemente hasta la quinta hora, se reúnen de nuevo en un mismo lugar, se ciñen un paño de lino y de esta manera se lavan el cuerpo con agua fría. Tras esta purificación acuden a una habitación privada, donde no puede entrar nadie que no pertenezca a la secta. Ellos mismos, ya purificados, pasan al interior del comedor como si de un recinto sagrado se tratara" (Bell 2,129).

22 LABAHN, Antje, "Aus dem Wasser kommt das Leben. Waschungen und Reinigungsriten in frühjüdischen Texten“, en David Hellholm (eds.), Ablution 157-208; LaWrence, Jonathan D., Washing 81-154; Harrington, Hannah K., Purity Texts (=Companion to the Qumran Scrolls 5), T \& T Clark, London - New York 2004.

23 Los textos del Mar Muerto no proporcionan información, por lo que se cuestiona la noticia de JoSEFO, Bell 2,129, para quien los esenios se bañaban con vestidos blancos. 
debía utilizar, aunque enfatizan que sea "agua viva", por lo que pudiera ser agua corriente de un arroyo, un manantial, una fuente o agua de lluvia almacenada en una cisterna.

La mayoría de las purificaciones rituales son lavados personales o autoabluciones sin la necesidad de sacerdote u otra persona. Sólo, en alguna ocasión, participa un sacerdote. En este caso, el agua se designa generalmente como agua de purificación y sirve para la expiación del pecado. Este aspecto moral, sin embargo, no jugó un papel relevante en el judaísmo de la época ${ }^{24}$, ya que las abluciones se centraban en el aspecto 'externo' con el objeto de proporcionar pureza ritual y, por consiguiente, posibilitar que las personas fueran capaces de entrar en contacto de nuevo con Dios mediante la participación cultual.

Los descubrimientos arqueológicos de las piscinas con escalera dentro del asentamiento de Qumrán pertenecientes a las diferentes fases históricas convencieron a varios autores de que el lavado ritual era un aspecto muy importante de la vida diaria de la comunidad 25 . Sin embargo, otros autores se muestran escépticos sobre los presupuestos ritualistas, alegando que estas piscinas estaban destinadas a diversos usos industriales, como pudiera ser la producción de cerámica 26.

La vinculación de la pureza ritual y moral, especialmente en la Rollos del Mar Muerto, pero también en Filón y Josefo, es instructiva para entender la postura del movimiento de Juan el Bautista y de Jesús. Además, se ha intentado relacionar la actividad bautista de Juan con los ritos lustrales de Qumrán por la proximidad geográfica y por la confesión conjunta y pública de los pecados; no obstante, la génesis de la praxis ritual del Bautista se ha buscado en otra dirección distinta, en el baño de inmersión de los prosélitos.

\section{c. El baño de inmersión de los prosélitos}

El bautismo cristiano presupone el de Juan el Bautista y se desarrolló a partir de él. Pero ¿de dónde adoptó Juan esa praxis bautismal?

${ }^{24}$ La situación es diferente en el material halájico de los rollos del Mar Muerto, que reflejan un desarrollo más tardío.

25 Magness, Jodi, The Archaeology of Qumran and the Dead Sea Scrolls, B. Eerdmans, Grand Rapids, Michigan - Cambridge 2002,147-158.

26 Sobre los testimonios arqueológicos de los miqva'ot cf. FrEYNE, Sean, "Jewish Immersion and Christian Baptism. Continuity on the Margins?", en David Hellholm (eds.), Ablution 230-236. 
Al margen de los esenios y del solitario asceta Banus (Josefo, Vit 1,11), grupos bautistas, como los hemerobaptistas, masboteos, sebueanos, elcesaitas, mandeos son conocidos solo para el período post-70 d.C. Por este motivo se ha intentado ver el origen de los ritos bautismales de Juan en el baño de inmersión de los prosélitos judíos ${ }^{27}$. Sin embargo, su origen, antigüedad, singularidad e importancia siguen siendo controvertidos.

Según la literatura rabínica ${ }^{28}$, existían tres exigencias para la conversión al judaísmo de un gentil: la circuncisión, la inmersión y el sacrificio. La circuncisión era el paso crucial para la conversión de un gentil varón al judaísmo (Ex 12,48-49) y constituía el marcador esencial de la identidad masculina judía, ya que conectaba a las personas con la historia de la alianza de Israel $^{29}$. Se desconoce sin embargo el objeto de incluir la exigencia de la inmersión, pues no se exigía a los judíos. Por eso se ha especulado sobre su origen. Dado que no existía un rito semejante a la circuncisión para las mujeres gentiles, parecería plausible la tesis de que hacia

27 Cohen, Shaye J.D., The Beginnings of Jewishness: Boundaries, Varieties, Uncertainties, University of California Press, Berkeley 1999, 198-238; SÄNGER, Dieter, "Ist er heraufgestiegen, gilt er in jeder Hinsicht als ein Israelit" (bYev 47b). Das Proselytentauchbad im frühen Judentum, en David Hellholm (eds.), Ablution 291-334; Feldman, Louis H., "Conversion to Judaism in classical antiquity", en HUCA 74 (2003) 115-156; BETZ, Otto, "Die Proselytentaufe der Qumrangemeinde und die Taufe im Neuen Testament", en Otto BetZ, Jesus. Der Herr der Kirche (=WUNT 50), J.C.B. Mohr (Paul Siebeck), Tübingen 1990, $21-48$

28 Midrash tanaítico SifBam 108 a Num 15,14 (Judá ha-Nasi, el Príncipe) y en bKer 9 a.

29 Para la discusión de si la circuncisión era un prerrequisito esencial de la conversión o un deber subsiguiente de la misma, cf. BIRD, Michael F., Crossing over sea and land: Jewish proselytizing activity in the Second Temple Period, Hendrickson Publishers, Peabody, MA 2009, 25-40, quien concluye que aunque las opiniones acerca de la aceptación de los gentiles en el judaísmo no eran uniformes, pues su complejidad deriva del problema de la autoidentidad judía en la antigüedad, sin embargo "circumcision was the ritual signifier that marks the difference between adherence and conversion. Pagans and Greeks, regardless of their adherence to Jewish customs or their association with Jewish communities, were still of the "nations" if they were uncircumcised. Only by circumcision could males become de jure Jews. We can make room for exceptions, account for misinterpretation of Jewish views by outsiders, recognize the elastic nature of group boundaries in certain settings; even so, circumcision was the primary expression of entering into the commonwealth of Israel for converts. Overall, then, we possess here an array of evidence that clearly marks out circumcision as the ordinary rite of passage for Gentile males to join Israel and to enter into covenant with their God, Yahweh" (34s.). 
mediados del siglo I a.C. las mujeres gentiles que desearan convertirse al judaísmo, tuvieran que someterse a un baño de inmersión, que servía de purificación cultual y testimonio de su pertenencia a la comunidad judía ${ }^{30}$.

Si esa datación fuera correcta, entonces el baño de inmersión de los prosélitos hubiera podido servir de modelo, al menos en su forma externa, para la configuración del bautismo de Juan. Este habría adaptado el rito destinado a los conversos paganos y le habría otorgado un nuevo contenido para sus contemporáneos judíos. Para justificar esta posición se aducen rasgos comunes a ambos rituales: a) singularidad: son únicos e irrepetibles; b) se requiere un agente ritual externo; c) se realizan mediante la inmersión; d) están vinculados a la idea del perdón de los pecados. Pero estas convergencias no son criterios suficientes para fundamentar el estatus especial del baño de inmersión de los prosélitos en el contexto de las abluciones corporales dentro del judaísmo antiguo.

La mayor dificultad radica, sin duda, en que no existen evidencias inequívocas acerca de la existencia de este baño de inmersión de los prosélitos antes del periodo de los tanaítas, es decir, una datación tardía. La mención de los baños de inmersión de los prosélitos en la Mishná y su supuesta existencia en otros textos rabínicos conformarían, según algunos investigadores, su origen anterior a la destrucción del templo ${ }^{31}$. Otros, por el contrario, juzgan de forma mucho más escéptica la validez de las afirmaciones de los textos rabínicos ${ }^{32}$, especialmente por lo que hace referencia a su terminus a quo. Se debe explicar por qué autores judíos contemporáneos ignoran el baño de inmersión de los prosélitos: no viene mencionado en la literatura intertestamentaria (apócrifos, pseudepígrafos, José y Asenet) y escritores como Filón y Josefo parecen desconocerlo. Judit 14,10 sólo menciona la creencia en Dios y la circuncisión como requisitos para la integración total de los gentiles en el pueblo de Israel. Este silencio podría hacer pensar que el baño de inmersión, como acto ritual añadido a la circuncisión en el proceso de conversión, adquirió sólo después del año 70 d.C. la significación que le atribuyen la Mishná y el Talmud.

30 Sobre la conversión de las mujeres gentiles, cf. IBID. 42 s.

31 Para una datación temprana del baño de inmersión de los prosélitos se apoyan en TestLev 14,6; Sib 4.162-169; EpICTETO, Diss II 9,19-21.

32 Textos rabínicos con referencias al baño de inmersión de los prosélitos: $m$ Pes 8.8 (= mEd 5,2); bYev 46a; tPes 7,13 (ed. Zuckermandel 167) bYev 47a-b; tratado Gerim. cf. Dieter SÄNGER, "Ist er heraufgestiegen" 311-322. 
Por consiguiente, los pocos puntos de contacto entre ambos ritos no son suficientes para poder establecer una relación más allá de los aspectos comunes externos entre el bautismo de Juan y el baño de inmersión ritual de los prosélitos. Además, la evidencia de su práctica antes y durante el tiempo de Juan no es concluyente ni determinante. Más bien, no hay ninguna referencia explícita a la inmersión de los prosélitos para nuestro período.

Si el baño de inmersión de los prosélitos no ha servido de modelo para el bautismo de Juan, entonces cualquier intento de derivación genética de su bautismo de un cierto tipo de abluciones judías, a pesar de las analogías formales y de contenido, permanece siendo hipotético. Más bien, el decidido ímpetu escatológico y ético de su bautismo debe ser considerado como una innovación del Bautista. Dada su relevancia para nuestro tema, le dedicaremos un epígrafe especial a este personaje tan característico dentro del judaísmo contemporáneo de Jesús.

\section{Juan el Bautista}

Juan ha pasado a la historia por la administración de su rito de inmersión, $\beta \alpha \tau \tau \iota \sigma \mu \alpha$, actividad que ocasionó su epíteto "bautista" ( $\beta \alpha \pi \tau \iota \sigma-$ $\tau \eta \dot{\zeta})$. Parte de las fuentes cristianas, en concreto, la tradición narrativa de los evangelios (Mc 1,2-6; Mt 3,1-16; Lc 3,1-6; Jn 1,19-23) ${ }^{33}$ consideró su bautismo como el antecedente del bautismo cristiano ${ }^{34}$, lo cual se vislumbra en el empleo de la terminología y en la atribución de la misma función, "perdón de los pecados".

33 Las cartas paulinas interpretan, por regla general, la existencia transformada de la persona cristiana gracias al bautismo en términos de su relación con Dios, con Cristo y/o con la comunidad. Para la presentación de Juan el Bautista en las tradiciones sinópticas cf. ERnst, J., Johannes der Täufer - der Lehrer Jesu? (=Biblische Bücher 2), Herder, Freiburg 1994,11-50; MüLlER, Ulrich B., Johannes der Täufer: Jüdischer Prophet und Wegbereiter Jesu (=Biblische Gestalten 6), Evangelische Verlagsanstalt, Leipzig 2002,100-162; BACKHAUs, K., "Echoes from the Wilderness: The Historical John the Baptist", en T. HOLMÉn - S. E. PORTER (eds.), Handbook for the Study of the Historical Jesus. Vol. 2: The Study of Jesus, Brill, Leiden 2011,1747-85; MEIER, John P., Un judío marginal. Nueva visión del Jesús histórico. Tomo II/1. Juan y Jesús. El reino de Dios, Verbo Divino, Estella 2001, 47-138.

34 LuPIERI, E.F., "John the Baptist in New Testament Traditions and History", en ANRW II 26,1 (1993) 430-461; ChiLton, Bruce, "John the Baptist: His Immersion and his Death" y Evans, Craig A., "The Baptism of John in a Typological Context", en Stanley E. Porter - Anthony R. Cross (eds.), Dimensions of Baptism. Biblical and Theological Studies (=JSNTS 234), Sheffield Academic Press, Sheffield 2002, 25-44 y 45-71. 
Este profeta del desierto se caracterizó por su rito bautismal en el río Jordán, que implicaba la confesión de los pecados (Mc 1,5), rasgo no inventado por los cristianos, pues planteaba problemas para el bautismo de Jesús. De hecho, Mateo lo ha suprimido. Se discute si el perdón de los pecados acontecía en el momento del bautismo o con el arrepentimiento previo. Qumrán y Josefo parecen optar por la segunda opción, mientras que los evangelios vinculan el perdón de los pecados al acto del bautismo (Mc 1,4; Lc 3,3). Según la concepción uniforme del cristianismo naciente, el bautismo era "con el objeto de", no "la causa" del perdón de los pecados (Hch 2,38) ${ }^{35}$. Por consiguiente, la sucesión del proceso ritual sería: a) conversión interior; b) confesión pública de los pecados; c) baño de inmersión; d) perdón de los pecados.

La fuente de los logia recoge un elemento relevante de su predicación: "ya está puesta el hacha a la raíz de los árboles. Y todo árbol que no dé buen fruto será cortado y arrojado al fuego" (Q 3,9). En este mundo conceptual se entrevé el horizonte de la parusía inminente y del juicio celestial, desde el que la concepción bautismal y su autocompresión adquieren su visión teológica y escatológica. La invitación a la conversión y al bautismo se encuentran en el horizonte de la espera de que la intervención divina acontezca de forma inminente, por lo que la persona se debe preparar mediante una conversión de la forma de vida previa, que se expresa gracias a la confesión de los pecados y se sella en el bautismo. La perentoriedad del juicio final hacía que el bautismo fuera un acto único e irrepetible, ya que no existía la posibilidad de pecar de nuevo, ni la necesidad de un nuevo bautismo. En este contexto se ha considerado el ritual joánico como un "sacramento escatológico".

En su predicación, Juan distingue entre un bautismo de agua y un bautismo con espíritu Santo: "Yo os bautizo [con] agua para conversión, mas el que viene detrás de mí os bautizará en espíritu Santo y fuego" (Mt $3,11)$. Los cristianos bautizan sólo con agua y no se dice en los evangelios que Jesús bautizará con espíritu. De los tres componentes, en Marcos falta el fuego, que sin duda pertenecía al estrato más antiguo. En el AT, el fuego acompaña a las teofanías y representa la imagen del juicio como elemento destructor y purificador. Esta imaginaría se encuentra en conformidad

35 Mt 3,11 tiene la construcción excepcional, "Yo os bautizo en agua para arrepenti-

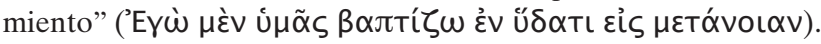


con la predicación del Bautista, quien proporciona un "seguro" para el tiempo final con ayuda del signo externo del agua, antes de la llegada del juez, quien bautizará con fuego (metáfora para el juicio).

\section{a. Contexto religioso-cultural de la actividad de Juan}

En los epígrafes precedentes se ha insinuado la relación del bautismo de Juan con algunos de los lavados judíos, especialmente con el bautismo de los prosélitos y los baños de los esenios. Al igual que todos estos, el bautismo de Juan consistía en una inmersión. Se diferenciaba, sin embargo, en que era un rito administrado por un agente ritual, es decir, no se trataba de una auto-inmersión. Asimismo, compartía con el resto de las abluciones judías la función de purificación o limpieza. No obstante, en lugar de constituir una purificación ceremonial o ritual, la praxis bautismal de Juan se caracterizaba por ser una purificación escatológica ante el juicio venidero de Dios. Si bien es verdad que en Qumrán también existía una expectativa escatológica, esta no estaba vinculada a las inmersiones; además, su enfoque era separatista-sectario y no dirigido a toda la nación. Por otro lado, el bautismo de Juan no constituyó una variante del baño de inmersión de los prosélitos ${ }^{36}$. En resumen, se puede afirmar que el simbolismo profético diferenciaba la praxis bautismal de Juan de otros lavados judíos.

E. Ferguson enumera la siguiente lista de funciones adscritas o implícitas en el bautismo de Juan: 1) Expresaba un arrepentimiento de conversión, es decir, un cambio a una nueva forma de vida;2) él mediaba para el perdón divino; 3) purificaba de la inmundicia, tanto ritual como moral;4) anunciaba el ministerio de una figura esperada (desde la perspectiva cristiana esto hizo que Juan fuera el precursor de Jesucristo), por lo que tenía una dimensión escatológica. 5) Era una iniciación al verdadero Israel, destinada no para una comunidad cerrada y exclusivista como era el caso en

36 Las diferencias entre el bautismo de Juan y el de los prosélitos son claras: a) El baño de los prosélitos se restringe por definición a los gentiles, el bautismo de Juan se dirige a los judíos (Q 3,7s; Mc 1,5; Mt 3,5; Josefo, Ant 18,118). b) El aspecto escatológico asociado al bautismo de Juan (Q 3,9.17s; Mc 1,7s.) no juega ningún papel en el baño de inmersión de los prosélitos. c) Mientras que el bautismo de Juan muestra una distancia significativa hacia el culto del templo, el baño de inmersión de los prosélitos está estrechamente relacionado con la ofrenda del sacrificio. d) El bautismo de agua de Juan no es un acto iniciático, ni otorga al neófito una nueva condición legal o religiosa, sino la reintegración entre los descendientes de Abrahán. 
Qumrán, sino para el pueblo de Dios renovado. 6) Constituía una protesta contra la organización del templo, ofreciendo un medio alternativo para el perdón de los pecados ${ }^{37}$.

Aunque diversos estudios ya han examinado con detalle el significado y la función del rito de Juan ${ }^{38}$, al igual que su contexto religioso-cultural, pocos se han planteado la cuestión de cómo contribuyó su innovación ritual de la inmersión a la consolidación de sus ideas religiosas y su funcionamiento como catalizador de su movimiento emergente.

\section{b. La innovación ritual de Juan}

Juan fue un emprendedor ritual. Se discute sin embargo dónde radicaba la novedad de su ritual. Se puede afirmar que la gran innovación de Juan fue la institución de un nuevo rito, barato, generalmente disponible, divinamente autorizado y eficaz para la remisión de los pecados. Su rito de inmersión proporcionaba a los campesinos, que difícilmente podían costearse ofrecer los sacrificios prescrito en el templo de Jerusalén, un medio económicamente accesible de expiación, aunque en tiempos de Jesús, la oración penitencial, los ayunos y los signos de duelo podían ser sustitutorios de los sacrificios del templo. Además, es significativo que la confesión pública de los pecados, las oraciones penitenciales y los ayunos también aparezcan vinculados a Juan (Mc 1,5; 2,18; Lc 11,1). Por consiguiente, Juan no refleja el rechazo frontal del templo, sino que puede ser alineado con varias prácticas y expresiones del judaísmo que ofrecen evidencias acerca de otros medios de arrepentimiento al margen del templo.

Si la idea central del mensaje de Juan consistía en que las purificaciones previas eran inefectivas sin un cambio moral, ¿qué es lo que hacía que sus inmersiones fueran extraordinarias? Diversos investigadores han considerado la inmersión de Juan como un rito de iniciación al movimiento bautista, administrado una sola vez para cada individuo ${ }^{39}$, mien-

37 Ferguson, Everett, Baptism in the Early Church. History, Theology, and Liturgy in the First Five Centuries, William B. Eerdmans, Grand Rapids, Mich. 2009, 93.

38 WeBb, Robert L., John the Baptizer and Prophet. A Socio-Historical Study (=JSNT 62), Sheffield Academic Press, Sheffield 1991,163-214; TAYLOR, Joan E., The Immerser. John the Baptist within Second Temple Judaism, William B. Eerdmans, Grand Rapids, Mich. 1997, 40-100.

39 WebB, John 197-202; Ferguson, Baptism 87. 
tras que otras formas de baños rituales judíos eran repetidas en multitud de ocasiones a lo largo de la vida para recuperar la pureza cultual. No obstante, no es concluyente que la inmersión de Juan actuara como un rito de iniciación. Para Risto Uro, la originalidad de su práctica ritual radicaba fundamentalmente en la forma del ritual y no tanto en su función ${ }^{40}$. Las abluciones rituales judías eran administradas personalmente por quien las recibía, mientras que en la inmersión de Juan se requerían dos personas: un agente ritual sobrehumano postulado cultualmente (Juan o su discípulo, un profeta enviado por Dios [Q 7,26]) y un paciente ritual (la persona que venía a él para ser bautizada). Su ritual no se podía repetir (cuando los dioses hacen algo, lo hacen para siempre) y contenía una gran carga sensorial. Por esta razón, desencadenaba una gran excitación emocional y jugaba un papel significativo a la hora de motivar a los miembros de un grupo. Los neófitos consideraban intuitivamente que el ritual, con Juan como agente especial y dejándose sumergir por él (heterobautismo), era más eficaz que una purificación ritual autoadministrada. Eso se constata en que la gente venía para ser bautizada por él y su rito de inmersión tuvo un éxito sin precedentes entre sus contemporáneos.

Según la teoría de Whitehouse ${ }^{41}$, las tradiciones religiosas surgen en torno a rituales creativos (imagistic) infrecuentes y altamente sensoriales o en el contexto de rituales (doctrinales) reiterativos. Los primeros desencadenan recuerdos duraderos y propician su transmisión. Al mismo tiempo, las cuestiones que atañen a uno mismo y donde uno se halla implicado, se recuerdan mucho mejor. Por este motivo, la inmersión de Juan fomentaba la decisión personal del paciente y la estructura de su ritual reforzaba la idea de que el paciente recibía una atención especial por parte del agente ritual, lo que hace que el encuentro fuese más memorable. Así, la inmersión de Juan pudo ser vista como un ritual que producía una elevada carga sensorial, originando recuerdos duraderos (aunque no necesariamente uniformes) en los participantes. Además, la autoimplicación en el bautismo fue un rasgo importante para acrecentar el recuerdo. Por otra parte, la actuación ritual poderosa de Juan y su estilo de vida austero ayudaron a la expansión y transmisión

\footnotetext{
${ }^{40}$ Uro, Risto, Ritual and Christian Beginnings. A Socio-Cognitive Analysis, Oxford University Press, Oxford 2016, 84s.

41 Whitehouse, Harvey, Modes of Religiosity. A Cognitive Theory of Religious Transmission, AltaMira, Walnut Creek, CA 2004, 72ss.
} 
de su mensaje ${ }^{42}$. Estas conclusiones pueden explicar en parte por qué han pervivido tantas tradiciones acerca de su persona y que su innovación ritual influyera en el cristianismo.

Por otra parte, su inmersión exigía un alto coste de compromiso para quienes recibieron su bautismo, ya que requería la confesión de los pecados (Mc 1,5) de forma pública, individual y personal. Ello implicaba que contenía costes sociales y emocionales que potenciaban la cohesión social y la solidaridad en la comunidad, juntamente con otros rasgos simbólicos, como las prácticas del ayuno y la oración.

Para quienes se bautizaron pero no permanecieron con el Bautista, sino que regresaron a sus casas y continuaron con su forma de vida cotidiana, la inmersión no funcionó como una señal costosa, sino como una señal carismática. Para otros, por el contrario, la inmersión de Juan fue tan impactante que coordinó sus pensamientos y comportamientos, de tal forma que pudo surgir un movimiento popular en torno a su persona. Por supuesto esta coordinación era embrionaria e incluía que quienes vinieron a Juan, creyeron que era un verdadero profeta. Tal fue la opinión de Jesús.

\section{El baUtismo CRISTiano}

El origen del bautismo cristiano es una cuestión compleja. Por un lado, encontramos noticia(s) o relato(s) de que Jesús fue bautizado por Juan (el Bautista): informan del bautismo de Juan, del bautismo de Jesús a manos de Juan y del don del Espíritu. Por otro lado, numerosos escritos del cristianismo primitivo testimonian la existencia del bautismo en el nombre de Jesús como ritual cristiano. Pablo es el testimonio literario más antiguo, quien a su vez se apoya en tradiciones bautismales previas, que reelabora de forma creativa. Todos estos textos, sin embargo, no están interesados en clarificar cómo se ha llegado a la práctica cristiana del bautismo, sino que la presuponen como el rito de acceso para los neófitos en la comunidad cristiana; una excepción constituye Mt 28,18-20, un episodio conocido como el "relato de la institución" del bautismo, cuyo valor ya hemos indicado al inicio del artículo. Un "eslabón perdido" de conexión

42 MeIser, Martin, "Johannes der Täufer als Asket", en Hans-Ulrich WeIdEmanN (ed.), Asceticism and exegesis in Early Christianity. The Reception of New Testament Texts in Ancient Ascetic Discourses, Vandenhoeck \& Ruprecht, Göttingen 2013, 78-91. 
entre ambos pilares históricos pudiera constituir la actividad bautismal de Jesús, que se encuentra sólo en Jn 3,22; 4,1, cuya memoria histórica subyacente es cuestionable. Los datos literarios han conducido a diferentes modelos de interpretación ${ }^{43}$, lo que sugiere la ambigüedad de las fuentes. Comencemos sin embargo por algo en lo que todos los estudiosos coinciden, el bautismo de Jesús.

\section{El bautismo de Jesús}

El bautismo de Jesús pertenece a los datos históricos más seguros de los recuerdos acerca de Jesús en el cristianismo primitivo y fue recogido en todas las tradiciones evangélicas (relato del bautismo: Mc 1,9-11; Mt 3,13-17; Q 3,21s; Jn no lo contiene, pero alude a él; asume que el hecho es conocido, lo recuerda e interpreta ${ }^{44}$ ) y en las primeras formulaciones del kerigma primitivo apostólico (Hch 1,22;10,37). El evento fue de gran relevancia para la autoconciencia de Jesús y la inauguración de su actividad pública ${ }^{45}$. Igualmente influyó en sus seguidores, quienes lo interpretaron muy pronto como la unción e indicativo de su papel mesiánico (Hch 10, 38). Además, aunque el NT nunca afirma que el bautismo de Jesús constituyó el fundamento o prototipo del bautismo cristiano, sin embargo la

43 Existen diversos modelos: a) continuidad entre la actividad bautismal de Jesús y la de la primitiva comunidad cristiana; b) aunque existió una breve actividad bautismal por parte de Jesús, esa praxis irrelevante, sin embargo, no explicaría el bautismo cristiano; c) la praxis cristiana del bautismo surgió de un recuerdo o memoria del bautismo de Jesús a manos de Juan; d) derivación de la práctica bautismal del cristianismo primitivo del bautismo de Juan en el que se conectan el argumento genético y fenomenológico; e) los episodios bautismales están al servicio de la práctica bautismal cristiana posterior ("leyendas bautismales").

44 El objetivo del bautismo de Juan era revelar a Jesús (1,31). Cf. STOwASSER, Martin, Johannes der Täufer im Vierten Evangelium. Eine Untersuchung zu seiner Bedeutung für die johanneische Gemeinde (=ÖSB 12), Österreichisches Katholisches Bibelwerk, Klosterneuburg 1992; WeBB, Robert L., "Jesus in relation to John 'the testifier' and not 'the baptizer'. The Fourth Gospel's portrayal of John the Baptist and its historical possibilities", en Paul N. Anderson - Felix Just, S.J. - Tom Thatcher (eds.), John, Jesus, and history, Volume 3: Glimpses of Jesus through the johannine lens, SBL Press, Atlanta 2016, 215 - 230.

45 ApEl, Matthias, Der Anfang in der Wüste - Täufer, Taufe und Versuchung Jesu. Eine traditionsgeschichtliche Untersuchung zu den Überlieferungen vom Anfang des Evangeliums (=Stuttgarter Biblische Beiträge 72), Katholisches Bibelwerk, Stuttgart 2013; ERNST, J., Johannes der Täufer. Interpretation - Geschichte - Wirkungsgeschichte (=BZNW 53), Walter De Gruyter, Berlin - New York 1989, 206-210. 
declaración de la filiación de Jesús y la venida del Espíritu Santo sobre él proporcionaron un claro paralelismo para el bautismo cristiano: el bautizado recibe el don del Espíritu Santo y se incorpora a "los hijos de Dios".

Si el bautismo de Juan se presentaba como un ritual de purificación de los pecados mediante su confesión pública (Mc 1,5; Lc 3,3; Mt lo ha suprimido), en el caso de Jesús, sin embargo, no aparece ese elemento (Mc 1,910). Ya era muy llamativo que Jesús hubiera sido bautizado por Juan, sin embargo no podían ir tan lejos como para narrar una confesión de los pecados de Jesús. Ello constituyó un problema para la tradición cristiana como se constata en los textos paralelos del resto de los evangélicos: Mt refleja un debate cristológico acerca del episodio bautismal, que consiste en la posible problematización de la preeminencia de Jesús frente al Bautista mediante el acto del bautismo $(3,14 \mathrm{~b})$, Lc minimiza la narración $(3,21 \mathrm{~s})$ y Jn no narra nada al respecto ${ }^{46}$. Sólo Lucas menciona que Jesús estaba orando en su bautismo, pero la oración tiene lugar después del bautismo, por lo que no fue una oración de penitencia. El Espíritu, identificado como Espíritu Santo, desciende mientras Jesús estaba orando. Su venida en forma de paloma es la única característica del bautismo de Jesús común a los evangelios.

Otra indicación que aparece en los cuatro evangelios, es el testimonio de Juan el Bautista acerca del futuro bautismo "en el Espíritu Santo", que será administrado por Jesús (Mc, 1,8; Jn 1,33). Juan también identifica a Jesús como el que quita el pecado del mundo (Jn 1,29). Por lo tanto, su testimonio atribuye a Jesús dos características básicas de la era cristiana, el perdón de los pecados y la concesión del Espíritu Santo.

Si tenemos en consideración la tradición más antigua, el relato del bautismo de Jesús constituía un breve texto narrativo, en el que Marcos realizó pocas modificaciones. Es muy probable que se transmitiera de forma aislada durante un tiempo, sin conexión directa con la tradición del Bautista, con la que Mc presenta ahora una estrecha relación. Se puede estructurar de forma binaria:

46 En el evangelio judeocristiano de los nazarenos se dice: "Mira la madre del Señor y sus hermanos le dijeron: 'Juan el Bautista bautiza para el perdón de los pecados, vamos allí para bautizarnos'. Sin embargo, él les respondió: '¿Acaso he pecado yo para tener que ir ante él y bautizarme?'” (Jerónimo, adv. Pelag. Ill 2, tomado de SCHNEemelcher, Wilhelm, New Testament Apocrypha. Gospels and related Writings, James Clarke \& Co - Westminster John Knox Press, Louisville - London 1991, 160). Este ejemplo muestra la gran dificultad que planteó a la primitiva tradición cristiana el hecho de que Jesús se sometiera al bautismo para el perdón de los pecados realizado por Juan. 
- Relato informativo: contiene en esencia el fundamento histórico (v.9)

- Su interpretación: visión (v. 10) y audición (v 11)

El acontecimiento originario (y la audición) afecta en Mc sólo a Jesús: no se dice nada de los que estaban presentes (Mc 1,5), sino que el bautismo es un hecho que acontece entre el Bautista y Jesús, la visión y la audición sólo entre Jesús y el cielo. Ello adquiere en Mc un significado narrativo elevado, pues el reino de Dios, que Jesús predicará, se encuentra oculto, escondido. Por el contrario, en Mt el suceso está dirigido a los presentes (Mt 3,17), al tiempo que en Lc el espíritu incluso se hace claramente visible (Lc 3,22), mientras que en Jn los acontecimientos que tienen lugar durante el bautismo de Jesús son un signo solamente para Juan el Bautista. Se observa cómo esta perícopa fue creciendo y transformándose.

El contraste entre el mensaje del Bautista y el de Jesús hace difícil explicar por qué Jesús sintió la necesidad de bautizarse. Este problema tal vez se pueda solucionar con ayuda del ev. de Juan. Según este evangelio, los primeros discípulos de Jesús procedían de los círculos del Bautista y muy probablemente existió una etapa desconocida de la vida de Jesús, en la que mantuvo una relación más estrecha con Juan el Bautista de lo que nos permiten entrever nuestras fuentes: él y sus discípulos provendrían del movimiento bautista ${ }^{47}$ y posteriormente emprendió su propio camino al reconocer que el mensaje del Bautista no era su mensaje: entre el anuncio del juicio de Juan (Q 3,7-9.16b-17), que contenía un aspecto salvífico con una conversión activa mediante el bautismo de arrepentimiento, y el ministerio de Jesús hay una diferencia fundamental, que condujo a que

47 Backhaus, K., Die 'Jüngerkreise des Täufers Johannes. Eine Studie zu den religionsgeschichtlichen Ursprüngen des Christentums (=PaThSt 19), Paderborn 1991; MANNING, Gary T., "The disciples of John (the Baptist): Hearers of John, followers of Jesus", en Steven A. Hunt - D. Francois Tolmie - Ruben Zimmermann (eds.), Character Studies in the Fourth Gospel. Narrative Approaches to Seventy Figures in John (=WUNT 314), Mohr Siebeck, Tübingen 2013, 127-132; Köstenberger, Andreas J., "Who Were the First Disciples of Jesus? An Assessment of the Historicity of the Johannine Call Narrative (John 1:35-51)", en Paul N. Anderson - Felix Just, S.J. - Tom Thatcher (eds.), John, Jesus, and history, Volume 3: Glimpses of Jesus through the Johannine lens, SBL Press, Atlanta 2016, 189-200. Para la cuestión de si Jesús fue discípulo de Juan, cf. MEIER, John P., Un judío marginal. Nueva visión del Jesús histórico. Tomo II/1: Juan y Jesús. El reino de Dios, Verbo Divino, Estella 2001, 159-175. 
Jesús desempeñara su misión de forma independiente y simultánea a la de Juan. En concreto, la esencia de la predicación de Jesús radicaba en el acontecimiento de la llegada del Reino de Dios que actuaba de forma poderosa durante su ministerio (cf. Q 11,19s.) y al que invitaba de forma incondicional.

Los relatos sinópticos del bautismo de Jesús están integrados en sus proyectos teológicos respectivos, en los que el bautismo de Jesús no aparece en relación con la práctica cristiana posterior del bautismo, al margen de la donación del Espíritu. Sólo la doble obra lucana traza una línea de sentido lingüístico explícito que conduce a la praxis bautismal del cristianismo primitivo, a la vez que pudo haber incluido elementos de la praxis bautismal de sus comunidades lucanas en la escena de Jesús. Por consiguiente, sería probablemente exagerado (1) desarrollar una derivación ininterrumpida de la actividad bautismal del cristianismo primitivo desde el bautismo de Jesús por Juan. El recuerdo de Jesús de los Sinópticos no deja espacio (2) para derivar esta praxis bautismal de una acción bautismal del propio Jesús. El silencio acerca de tal actuación y la nula vinculación de la predicación de Jesús con el bautismo hacen poco probable una actividad bautismal por parte de Jesús. Pero contemplemos esa posibilidad.

\section{La actividad bautismal de Jesús}

Los modelos explicativos, que interpretan el bautismo de Juan como modelo a seguir o el bautismo de Jesús como reflejo retrospectivo de una práctica comunitaria cristiana, es decir, una etiología bautismal, ambos modelos presuponen junto a la continuidad, una discontinuidad entre los acontecimientos prepascuales y pospascuales. Una actividad bautismal de Jesús o de sus discípulos constituiría un puente entre ambos, pues es claro que en el círculo de los primeros seguidores de Jesús se encontraban antiguos seguidores del Bautista (Jn 1,29s.).

El hecho de que la actividad bautismal de Jesús sea considerada como punto de enlace con la temprana práctica de la iglesia cristiana, se fundamenta en el testimonio del cuarto evangelio, quien informa que Jesús estaba comprometido en el ministerio de bautizar de forma paralela a Juan $(3,22-23.26 ; 4,1-2)^{48}$. Puesto que Jesús se identificó con el bautismo de Juan

48 ZimMERMANN, Heinrich, „Die christliche Taufe nach Joh 3, ein Beitrag zur Logoschristologie des vierten Evangeliums”, en Catholica 30 (1976) 81-93; CAMBE, Michel, “Jesus 
y su participación en el ministerio de Juan podría haber comprometido su superioridad respecto a Juan, el relato tal vez fue aceptado porque se pensó que estaba basado en la memoria histórica temprana. El hecho de que el Nazareno fuera bautizado y durante algún tiempo, junto con sus discípulos, practicara el bautismo explicaría fácilmente que los discípulos prosiguieran e implementaran esta práctica en el período pospascual ${ }^{49}$. Incluso R.T. France sugiere que Jesús continuó practicando ese rito lustral durante todo su ministerio: "Existen buenas razones para creer que el bautismo no cayó en desuso tras el encarcelamiento de Juan, solo para ser reintroducido inmediatamente después de la resurrección, sino que continuó siendo para Jesús, como lo había sido para Juan, el medio normal de adhesión de quienes optaban por vincularse a este movimiento de restauración escatológico. No sólo al inicio, sino a lo largo de todo su ministerio, Jesús fue un segundo 'bautista" "50. Por consiguiente, no deberíamos inferir que Jesús abandonara la praxis bautismal por el hecho de que no se mencione de forma explícita en el resto del evangelio. En opinión de Michaels, el evangelista Jn cree que Jesús desempeñó su ministerio bautismal y nunca menciona que cesara de esa praxis. Pero porque estaba convencido de que el bautismo de agua no confería el espíritu (incluso ni cuando Jesús era el agente ritual), entonces el escritor minimizó la temática del bautismo y, en su lugar, favoreció otra terminología tanto metafórica como no metafórica, "venir a Jesús", "creer en él”, comer el pan de vida... A pesar de minimizar el bautismo, existen indicios en Jn de que quienes vinieron y creyeron en Jesús pudieron ser bautizados y lo concibieron como un rito de iniciación ${ }^{51}$.

baptise et cesse de baptiser en Judee Jean 3:22 - 4:3", en Études theologiques et religieuses 53 (1978) 98-102; LEGASSE, Simon, "Le baptême de Jesus et le baptême e chrétien", en $L i$ ber annuus 27 (1977) 51-68.

49 LABAHN, Michael, "Kreative Erinnerung als nachösterliche Nachschöpfung. Der Ursprung der christlichen Taufe", en David Hellholm (Eds.), Ablution 337-376.

50 France, R.T., "Jesus the Baptist?”, en J.B. GreEn - M. Turner (eds.), Jesus of Nazareth: Lord and Christ. Essays on the Historical Jesus and the New Testament Christology, Eerdmans, Grand Rapids 1994, 94-111, aquí 107.

51 Michaels, J. Ramsey, Baptism and Conversion in John: A Particular Baptist Reading”, en Stanley E. PorTer - Anthony R. Cross (eds.), Baptism, the New Testament and the Church. Historical and Contemporary Studies in Honour of R.E.O. White (=JSNTS 171), Sheffield Academic Press, Sheffield 1999, 136 - 156,141. Este autor considera que no existen medios de probar o rechazar la propuesta de R.T. France, "pero si el ministerio de Jesús resultó, como Jn sugiere, en la creación de un grupo de discípulos, es normal suponer 
A pesar de los últimos juicios más positivos acerca de la fiabilidad histórica del cuarto evangelio ${ }^{52}$, hay que tener en consideración la fuerza creativa del narrador joánico, que conserva la "memoria" de Jesús, pero al mismo tiempo le confiere una nueva forma y la actualiza. Por tanto, se cuestiona si el proyecto teológico joánico es portador de un recuerdo de la actividad bautismal realizada por Jesús ${ }^{53}$ o si esa actuación hay que atribuirla a una construcción joánica. Esta última posibilidad es plausible y el lector la puede intuir en el hecho de que no se relate el bautismo de Jesús a manos de Juan. El narrador señaló con ello, que la memoria del bautismo de Jesús y el evento representado en él sirvieron para su presentación teológica o cristológica.

Al margen del testimonio del Bautista acerca de Jesús, el hecho del bautismo en Jn es irrelevante. Se juega con la memoria, pero la historia resultante es una nueva construcción motivada cristológicamente. Es claro que el tema del bautismo en el cuarto evangelio se convierte en un espacio de construcciones de significado cristológico, que combina diferentes tradiciones, pero no se puede utilizar de forma fiable como fuente histórica para la reconstrucción del bautismo realizado por Jesús.

¿Por qué Jesús, a pesar de su encuentro y bautismo con el Bautista, él mismo no bautizó? ¿Se trata de un deseo de separación fáctica de su maestro? La diferencia del mensaje de Jesús no radicaba en la alternativa entre la predicación de la salvación de Jesús y el anuncio del juicio del Bautista como punto central, del que se podía librar únicamente por un acto de arrepentimiento (bautismo) con la correspondiente transformación, sino en el acontecimiento inmediato y directo de la comunicación del mensaje y la promesa de la salvación, a la luz de la cual tenía lugar la nueva construcción teológica y social de los destinatarios directamente y más allá de una iniciación ritual.

Para la actividad bautismal de Jesús hay que analizar la información lacónica de Jn 3,22. Con la expresión introductoria, “después de esto”,

que fueron sometidos a algún tipo de proceso iniciático. Dado el precedente de Juan el Bautista y los amplios testimonios acerca del bautismo en la Iglesia antigua, 'water baptism is as likely as not to have been this procedure'" (152).

52 Véase la introducción al proyecto de la historicidad de Juan y el motivo de la necesidad del mismo en Anderson, Paul N. - Just, Felix S.J. - Thatcher, Tom (eds.), John, Jesus, and History. Volume 1: Critical Appraisals of Critical Views, Brill, Leiden - Boston 2007, 9-70.

53 MeIER, Un judio marginal 167, aboga por la actividad bautismal de Jesús durante su ministerio. 
relata un cambio de lugar de Jesús y sus discípulos a la región de Judea, donde estuvo un cierto tiempo con ellos. Esta estancia se describe como un período de actividad bautismal del propio Jesús, tal y como sugiere la forma verbal en imperfecto. A esta noticia sigue el episodio de la actividad bautista de Juan, presentando su actuación de forma simultánea y en competencia con Jesús (3,23ss.). Los discípulos del Bautista ven con recelo y disgusto el éxito de la actividad bautismal de Jesús, por lo que se lamentan ante su maestro. Pero Juan lo interpreta como voluntad divina y subraya su subordinación a Cristo (v.30). Junto a la determinación de las relaciones cristológicas entre el Cristo (v.28) y su testigo y la interpretación de Jesús como esposo escatológico (v.29), se puede leer 3,22-30 como testimonio de la valoración del bautismo en la comunidad joánica y, por tanto, como una indicación de la praxis bautismal en dichas comunidades. El texto no pretende ser una retroproyección historizante de la propia praxis bautismal al Jesús terreno, sino marcar su diferenciación frente al bautismo de Juan y subrayar una continuidad con la actividad de Jesús, que encuentra su destino en la cruz, pues, en última instancia, es allí donde se fundamenta la concepción sacramental joánica $(19,34)$.

El mayor éxito de la praxis bautismal de Jesús, en comparación con la del Bautista, viene enfatizada en Jn 4,1. La mención de los fariseos estructura el éxito de Jesús frente al Bautista en el esquema conflictivo joánico: esos, para quienes ya la actividad del Bautista como enviado $(1,19 \mathrm{ss})$ era sospechosa $(1,24)$, ponen en tela de juicio también la actividad del testimoniado para entregarlo finalmente a la muerte $(7,32 ; 11,47$; 18,3). Jn 4,1 contempla de forma proléptica el bautismo en la comunión con Jesús. El aspecto eclesiológico del bautismo realizado por Jesús nos lleva a considerar que Jn 4,1 no contiene un recuerdo histórico de la actividad de Jesús, sino que debe entenderse dentro de la trama narrativa del cuarto evangelio. Por su parte, Jn 4,2 -"aunque Jesús no bautizaba él mismo, sino sus discípulos"- bien pudiera ser una glosa más tardía en el proceso de una relectura joánica ${ }^{54}$, ya que no aparece en los sinópticos esa información de la actividad bautismal de los discípulos en vida de

54 Brown, Raymond E., El Evangelio según Juan. I-XII, Cristiandad, Madrid 1979, 366 , explica este añadido en la redacción final por el temor a que "los discípulos de Juan Bautista utilizaran el hecho de que Jesús bautizaba para decir que éste era tan sólo un imitador del primero". 
Jesús. El éxito de la actividad bautismal de los discípulos ilustra el tiempo pospascual. La relectura glosada de 4,1 mediante 4,2 proporciona una aclaración, ya que traslada la visión de la determinación de la relación del Bautista con Jesús a la praxis bautismal de la comunidad.

Jn menciona una actividad bautismal de Jesús, pero no su propio bautismo. Este hecho por sí solo invita a la prudencia a la hora de encontrar acontecimientos históricos en las noticias joánicas. Además, la predicación y la actividad de Jesús en los sinópticos nunca vienen relacionadas con ningún tipo de bautismo, a pesar de que en varias ocasiones aparece la invitación a la conversión y al arrepentimiento en boca de Jesús. Esta ausencia es sintomática y tal vez sea indicio de que la información joánica permita reconocer más bien la práctica del bautismo en la comunidad joánica en confrontación con grupos bautistas. También es evidente que se era consciente de la cercanía del bautismo cristiano a la actividad bautismal de Juan y, por consiguiente, era necesario establecer diferencias. De esta forma, Jesús se convierte en agente ritual y la propia práctica de la comunidad se relaciona con la actividad del Jesús terreno, que en la cruz encuentra el objetivo y el fundamento del bautismo. Al mismo tiempo, la propia actividad bautismal pospascual se data como una obra de los discípulos, que se basa en el establecimiento de los sacramentos en la muerte de Jesús, creando así una fusión de horizontes.

\section{Bautismo cristiano, creación pospascual en continuidad con el bautis- mo de Juan}

Los textos presuponen una praxis bautismal paleocristiana ampliamente extendida y aceptada muy pronto. La construcción de sentido reconocible en los textos más tardíos no debe fundamentar ni justificar de nuevo la práctica bautismal, sino desea generar sentido de la praxis bautismal en su contexto narrativo y/o retórico respectivo, es decir, en los espacios de comprensión y en la capacidad de maniobra para los destinatarios. Esto no contradice la suposición de que la construcción de sentido se produzca a través de la memoria histórica y al mismo tiempo son tenidos en consideración los impulsos para las construcciones históricas. Sin embargo, solo se pueden presentar algunas líneas generales y supuestos básicos para la reconstrucción de la génesis del bautismo paleocristiano. 
Estos incluyen:

a. la noticia históricamente aceptable del bautismo de Jesús por el Bautista, que era necesaria para la nueva aceptación del hecho del bautismo como rito normativo de entrada en la comunidad cristiana,

b. el bautismo de Juan como modelo para el nuevo bautismo del cristianismo primitivo, como testimonian una serie de hechos y paralelismos estructurales,

c. la observación o constatación de diferencias objetivas de contenido entre el bautismo de Juan y el bautismo del cristianismo primitivo, en especial la referencia constitutiva a Jesús que fundamenta una relación fenomenológica, pero no una conexión genética directa,

d. una praxis bautismal de Jesús que no se fundamenta a nivel histórico ni en la predicación ni en la presentación de los sinópticos, ni en Jn 3,22; 4,1, y por lo tanto no puede ser considerada como momento fundante de continuidad entre ambas actividades bautismales,

e. la memoria ausente en los textos del cristianismo primitivo de una institución del bautismo de parte del Jesús terreno y

f. la idea de la institución bautismal tras la muerte de Jesús, como un acto del resucitado, que contiene una clara señal de la memoria de la praxis bautismal como creación pospascual, que posiblemente se fundamentó muy pronto en la autoridad del resucitado.

Teniendo en consideración estas indicaciones, se obtiene el siguiente cuadro: en las comunidades cristianas primitivas se sintió muy pronto, aunque imposible determinar su datación, la necesidad de aceptar a neófitos en la primitiva comunidad cristiana mediante un acto ritual. Este acto fija la transformación de la persona dentro de la nueva comunidad, la cual debe igualmente su fundación y actividad a Cristo, del mismo modo que esta nueva vida se lleva a cabo como existencia en el ámbito de propiedad salvífica de Cristo mediante la pronunciación de su nombre en el bautismo. Se trataba de alguna sencilla fórmula bautismal que lo vinculaba de forma especial a Cristo ("en el nombre de Jesús), y que posteriormente se desarrolló hasta convertirse en una formulación triádica ("en el nombre del Padre y del Hijo y del Espíritu Santo"). El bautismo de conversión del Bautista, cuya memoria era problemática como acto de perdón en la comprensión del bautismo del Hijo de Dios Jesús, es un modelo inspirador como ratificación ritual del abandono de la vida anterior (cf. 
para el Bautista Mt 3,7-10 par. Lc 3,7-9 [Q]; para el bautismo cristiano: 1Cor 6,9-11; Hech 2,38.41) y su nueva orientación hacia Dios. Por consiguiente, la innovación ritual del bautismo de Juan fue adoptada por los seguidores de Jesús tras la Pascua y se convirtió en rito de iniciación de la Iglesia primitiva siguiendo el paradigma del bautismo de Jesús a manos de Juan. 